
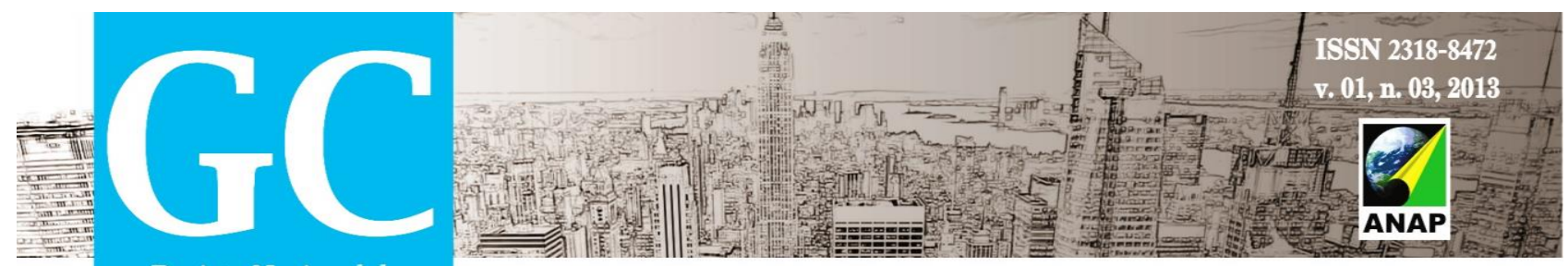

Revista Nacional de

Gerenciamento de Cidades

\title{
AUSÊNCIA DE SINCRONIA ENTRE PLANEJAMENTO E A ARBORIZAÇÃO URBANA: UM ESTUDO DE CASO NA AVENIDA RUI BARBOSA EM GARANHUNS - PE
}

\section{Ana Maria Severo Chaves ${ }^{1}$}

\section{Abraão dos Santos Silva²}

\section{Maria Betânia Moreira Amador ${ }^{3}$}

RESUMO: Diante do desenvolvimento urbano pode-se perceber grande preocupação com a população, seu bem estar, conforto, saúde entre outros benefícios que o homem urbano precisa ter. Nesse contexto, a introdução da arborização nas cidades por meio, principalmente, da formação de áreas verdes urbanas, como parques, praças, canteiros centrais ou calçadas melhoram a qualidade da vida urbana. Porém a falta de adequação entre o planejamento urbano e a arborização, acaba causando danos ao meio ambiente urbano afetando diretamente a população. Por isso o plantio de árvores nos centros urbanos precisa ser algo planejado, em que seja necessária a realização de estudos envolvendo as espécies arbóreas escolhidas mediante o espaço que vai ser arborizado. Nessa concepção, o presente estudo realizado com foco na arborização do Canteiro Central da Avenida Rui Barbosa em Garanhuns-PE, teve como objetivo diagnosticar a sincronia ou a sua ausência entre o planejamento urbano e a arborização urbana do Canteiro Central da Avenida Rui Barbosa de Garanhuns-PE, identificar as espécies arbóreas de grande e médio porte, bem como quantificar as mesmas. Para isso, adotouse o método qualitativo, analítico, quantitativo, registros fotográficos e observações in

\footnotetext{
${ }^{1}$ Graduanda de L. em Geografia pela UPE-Campus Garanhuns. E-mail: aninhasevero07@hotmail.com

${ }^{2}$ Graduado de L. em Geografia pela UPE-Campus Garanhuns. E-mail: abraaogeo2409@gmail.com

${ }^{3}$ Prof. ${ }^{a}$ Adjunta da UPE-Campus Garanhuns. E-mail: betaniaamador@yahoo.com.br
} 


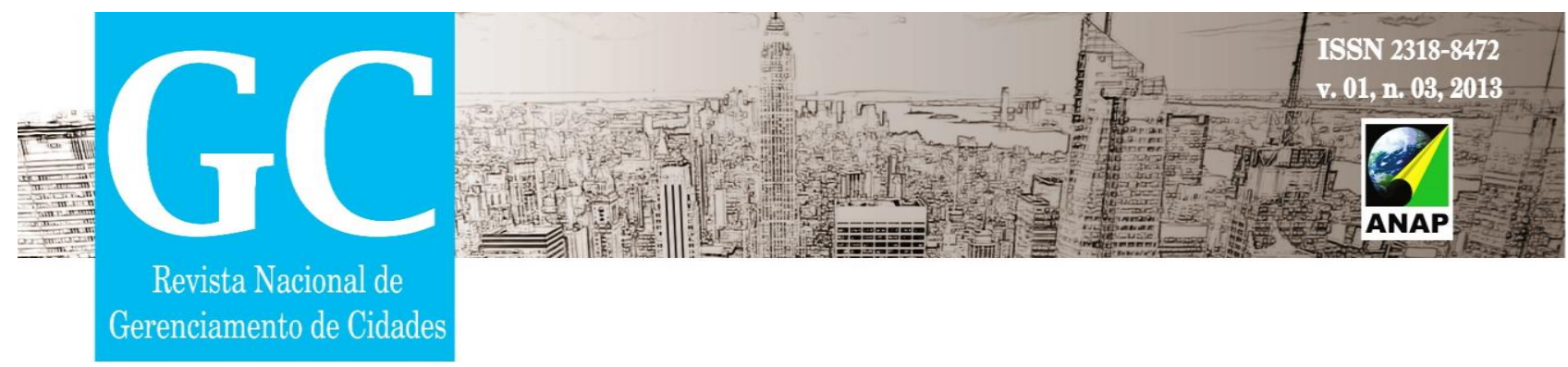

loco. Assim, diagnosticou-se a falta de sincronia entre o planejamento urbano e a maior parte da arborização presente no canteiro, pois a maioria das espécies arbóreas identificadas é exótica e de grande porte, ou seja, inadequadas para espaços pequenos e limitados.

Palavras chave: Planejamento urbano. Arborização urbana. Avenida Rui Barbosa.

\section{INTRODUÇÃO}

Os espaços públicos urbanos são espaços disponíveis para uso comum da população, independente de classe social, cultura ou etnia, é um bem comum a todos. Esses espaços são destinados ao plantio de espécies arbóreas, circulação, recreação e preservação ambiental beneficiando aos usuários de tais locais, bem como a população urbana em geral e ao próprio ambiente urbano, visto que a presença de árvores nos centros urbanos é um fator ecológico que causa bem estar à população e contribui para um melhoramento ambiental da própria cidade.

Esses espaços livres e arborizados desempenham varias funções benéficas nas cidades, porém quando se arboriza espaços urbanos é necessário que a arborização esteja em sincronia com os elementos construídos nas cidades e presentes nos próprios espaços livres de construção. Caso não exista essa sincronia entre a arborização e a cidade, essas áreas arborizadas acabam prejudicando o ambiente urbano e afetando principalmente a população.

Nesse contexto, a falta de sincronia entre as áreas arborizadas e não arborizadas, refere-se à falta de planejamento no momento de plantar árvores na cidade e, no caso especifico da arborização presente no Canteiro Central da Avenida Rui Barbosa em Garanhuns-PE, tem-se um exemplo da ausência de planejamento entre grande parte das espécies arbóreas escolhidas e o espaço destinado ao plantio. Pois o Canteiro se localiza numa das avenidas mais movimentadas de Garanhuns, é limitado e apresenta espécies 


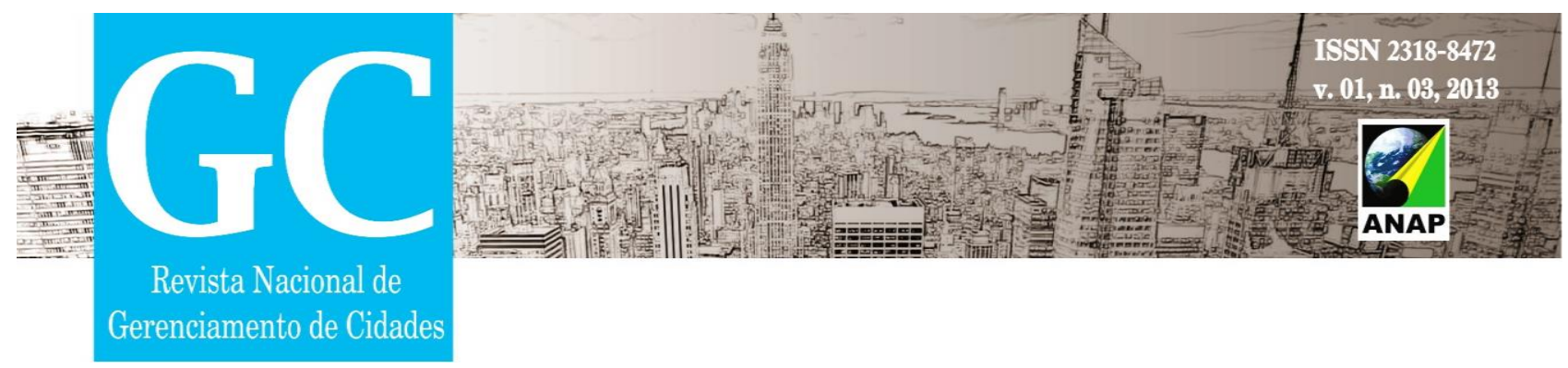

arbóreas de grande e médio porte, ou seja, são inadequadas para esses espaços de áreas exíguas, além de se apresentarem pouco permeáveis.

É importante esclarecer o entendimento que se tem de sincronização aplicado ao caso em estudo. Ou seja, o planejamento intrínseco ao município e sua administração deveria estar harmonizado com os elementos e critérios dispostos na literatura pertinente ao paisagismo urbano e arborização, também urbana. Dessa forma, poder-se-ia esperar um desenho paisagístico / urbano mais apropriado ao sítio de cada cidade levando-se em consideração itens importantes para todos como temperatura, umidade, estética, valorização patrimonial, em alguns pontos como atração e refúgio para micro e pequenos animais entre outros.

O presente trabalho apresenta os seguintes objetivos: diagnosticar a sincronia ou a ausência da sincronia entre o planejamento urbano e a arborização urbana do Canteiro Central da Avenida Rui Barbosa de Garanhuns-PE, identificar as espécies arbóreas de grande e médio porte e quantificar as principais espécies arbóreas. Para atingir tais objetivos adotou-se o método qualitativo analítico, quantitativo, registros fotográficos, observações in loco e um levantamento teórico sobre o tema abordado.

Assim, percebe-se que a arborização urbana não se resume apenas ao ato de plantar árvores em espaços livres. Neto e Souza citam que "A arborização urbana não significa apenas plantar árvores, mas segue uma série de atividades como manutenção e gerenciamento do patrimônio vegetal, cabendo aos órgãos públicos criar os meios que viabilizem a sua execução" (NETO; SOUZA, 2009, p 57). Pode-se concluir, então, que a introdução da arborização deve ser algo planejado, levando-se em consideração os espaços livres que vão ser arborizados e as espécies arbóreas escolhidas para o plantio bem como ter conhecimento sobre de quem é obrigação de gerenciar e fazer a manutenção desses ambientes e da própria árvore, de modo que proporcione a sincronia entre espaços arborizados e espaços edificados.

Caso contrário, ou seja, a falta de sincronia na inserção de árvores nas cidades se torna algo problemático em vez de benéfico. Salientando-se que, apesar de ser de responsabilidade dos órgãos públicos criarem os meios que viabilizem e executem a 


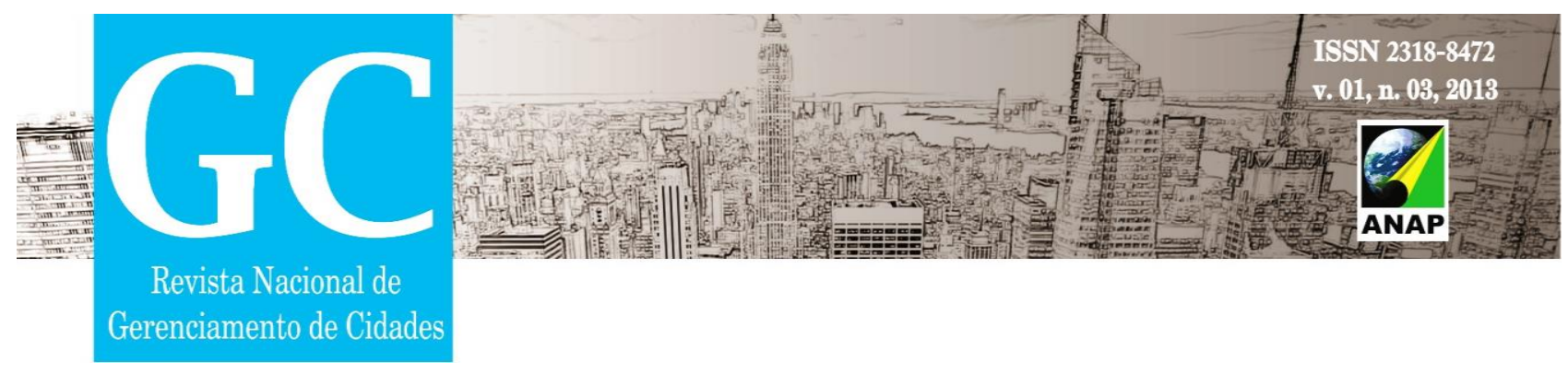

manutenção e gerenciamento das áreas arborizadas, é dever de todos cuidar e zelar pela integridade desses ambientes considerados como bem comum.

\section{SINCRONIA ENTRE A ARBORIZAÇÃO URBANA E A CIDADE}

Cidades, uma obra humana, um espaço construído para o homem habitar, organizar e representar a produção através do trabalho, lugar civilizado. Um espaço construído que, para Dardel (2011), é "a forma mais importante do espaço construído está ligado ao hábitat do homem (...) cidade compreende-se como um centro de relações" (DARDEL, 2011, 27).

A cidade também é percebida como oposição à natureza por ser pura construção humana, é vista por alguns autores como o habitat natural do homem civilizado (PARK 1936), um grande sistema, um grande recurso, é até mesmo uma negação da natureza, uma vez que, se trata em grande parte de algo feito pelo homem (HARVEY, 1973). Nesse sentido tem-se, ainda, que a moradia nas cidades é completamente antinatural, na medida em que é o resultado de um processo mental e intencional dos grupos humanos em oposição à vida em natureza (HOLANDA apud HENRIQUE, 2009, p.117).

Nessa obra inacabada do homem, a cidade mostra suas funcionalidades como indispensáveis a vida humana na contemporaneidade, mas também se mostra como insuficiente se não for unida a natureza. Fato esse comprovado pelas primeiras sociedades industrializadas, as quais viram na introdução de áreas verdes um fator que contribuí para a qualidade de vida das cidades, pois com o processo de fotossíntese realizado pelas plantas, a poluição urbana diminui Além dos inúmeros benefícios proporcionados pela presença arbórea nas cidades.

Assim, a presença da natureza no urbano se constitui numa natureza construída, adaptada a espaços construídos e limitado pelo homem. Nessa perspectiva Henrique (2009, p. 118) cita: 


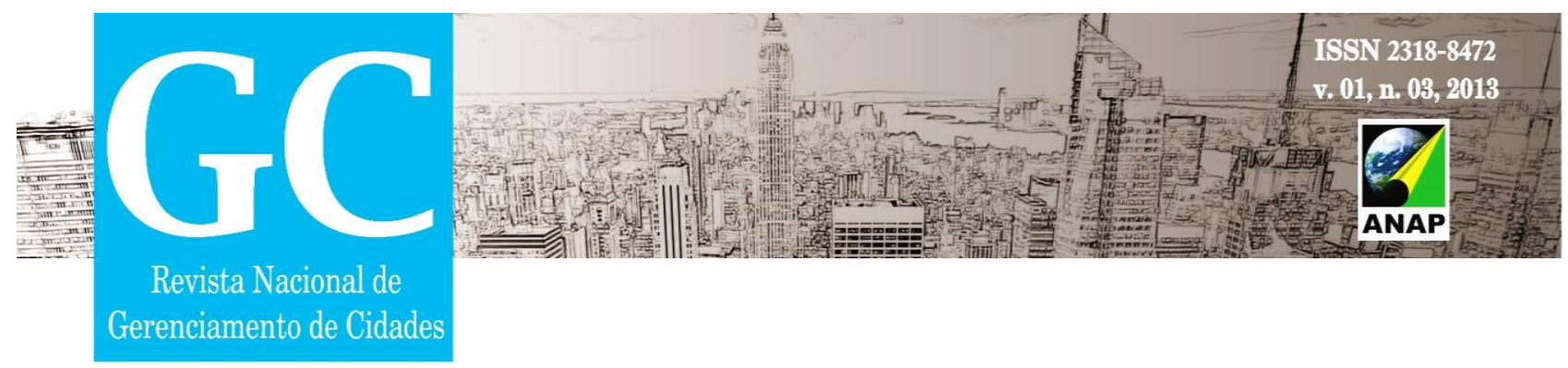

Infelizmente, a natureza na cidade, cujo elemento caracterizador será a vegetação, está confinada no desenho urbano a uma espécie de metonímia da natureza. Uma natureza racionalizada (em diferentes gradações), uma natureza construída, não uma representação direta da natureza, mas sim um modelo de natureza historicamente construído pela técnica, pela ciência, pela cultura, pela prática e pela ideologia. (HENRIQUE, 2009, P.118)

Assim, o homem ao destruir a natureza para construir a cidade, lugar civilizado, de conforto, relação social, vê-se também na necessidade de inserir no ambiente das cidades as áreas verdes, ou seja, adiciona uma natureza, porém não uma natureza natural, mas sim uma natureza humanizada resultante das técnicas, adaptada aos espaços livres urbanos, submetidas a ambientes hostis e artificiais.

Nessa adaptação de uma natureza construída, a artificialidade das cidades requer uma sincronia entre os elementos naturais dos espaços arborizadas com os espaços edificados. E são os espaços livres de construção, lugares destinados ao plantio das árvores, a presença do verde no seio urbano, a circulação e recreação da população fator esse essencial para o desenvolvimento saudável da vida urbana. $E$, tendo como consideração os espaços urbanos, pode-se classificá-los tomando-se como ponto de vista sua constituição física, como um conjunto de espaços edificados ou de espaços livres como conceitua Carneiro e Mesquita, onde:

Os espaços edificados são áreas ocupadas de maneira significativamente densa pelas construções que atendem as atividades do meio urbano: de uso residencial, comercial, industrial, de serviços de educação, saúde, educação, entre outras que, geralmente em proporção direta, em número e grau de complexidade, ao tamanho e importância do aglomerado populacional. (CARNEIRO; MESQUITA, 2000, p. 24).

De acordo com essas autoras, os espaços edificados são todas áreas ocupadas por construções e que exercem atividades particulares no meio urbano, ou seja, é um conjunto de áreas edificadas pelo resultado das ações humanas na estrutura urbana ao longo das gerações. Já espaços livres, no contexto dessa mesma estrutura, são aquelas áreas parcialmente edificadas com nula ou mínima proporção de elementos construídos ou de vegetação, como por exemplo, avenidas, ruas, vielas, entre outros. Ou com 


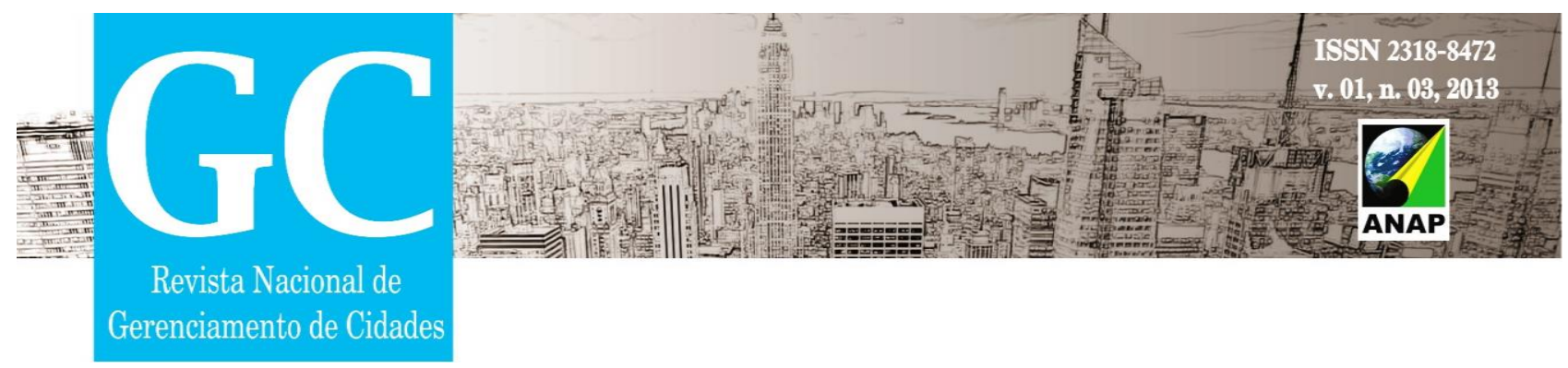

presença de vegetação, como por exemplo, praças, parques, jardins, canteiros, etc. que tem como funções no espaço urbano de recreação, circulação, composição paisagística e de equilíbrio ambiental (CARNEIRO; MESQUITA, 2000).

Essa denominação de espaço livre também está associada à condição de acesso a essas áreas sem restrições permitindo, assim, exercer sua função no contexto do espaço urbano. Dessa forma, para Schutzer (2012, p. 139) "Toda cidade é composta por volumes construídos e espaços livres, que estão dispostos em diversos matizes sobre um suporte geográfico". Pois, sendo a Geografia a ciência que estuda a superfície terrestre a as relações sociais e ambientes sobre ela, proporcionando explicações, ate certo ponto mensuráveis, a respeito das relações socioambientais nas cidades procurando entender a complexidade das relações e inter-relações dos espaços entre esses o urbano.

Também e posto a necessidade de melhorar as condições ambientais urbanas tão poluído devido as indústrias. Porém plantar uma árvore não é apenas introduzi-la em um espaço livre de construções, é necessário uma serie de cuidados que devem ser tomados pelo profissional responsável pela arborização, assim,

\begin{abstract}
Cabe, portanto, ao profissional que lida com as árvores identificar e compreender as características do local onde as plantamos nas cidades, a fim de escolher a espécie que melhor se adapta ao local e definir as melhores formas de intervenção para garantir seu desenvolvimento, sua longevidade e sua integridade. (MANUAL DE ARBORIZAÇÃO, 2011 p. 21).
\end{abstract}

Se medidas como, estudo da espécie escolhida para o plantio, do espaço disponível para o plantio da árvore não forem realizadas, o plantio acaba resultando na ausência de sincronia entre planejamento urbano e arborização urbana nos espaços públicos chegando a, por causa disso, causar danos tanto aos espaços livres como a própria população. Salientando-se que planejamento é,

Um processo contínuo e dinâmico que consiste em um conjunto de ações intencionais, integradas, coordenadas e orientadas para tornar realidade um objetivo futuro, de forma a possibilitar a tomada de decisões antecipadamente. Essas ações devem ser identificadas de modo a permitir que elas sejam executadas de forma adequada e considerando aspectos como o prazo, custos, 


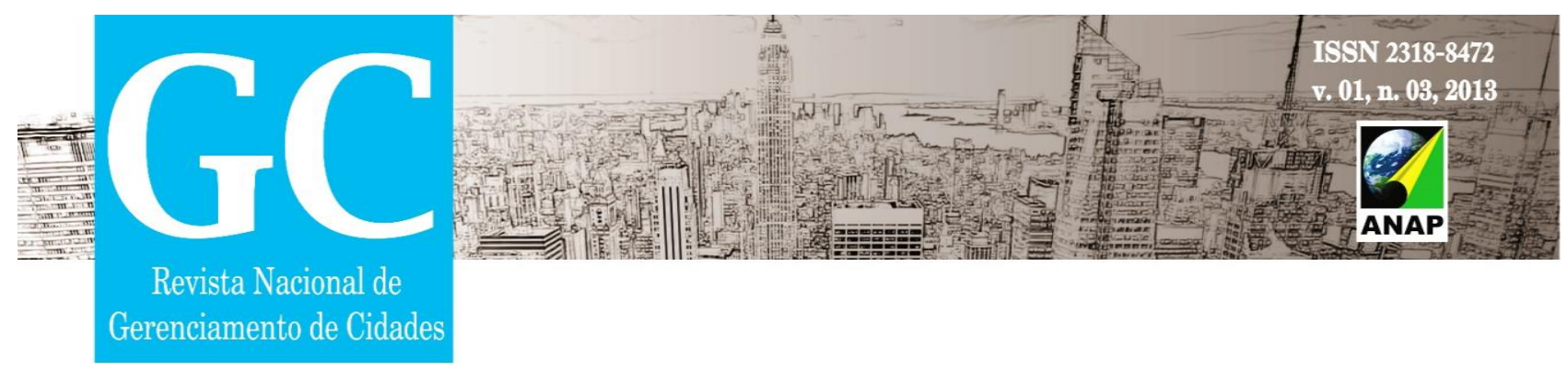

qualidade, segurança, desempenho e outras condicionantes. (Disponível em: http://www.administradores.com.br/artigos/administracao-e-negocios/).

Por isso, ao se planejar arborizar áreas livres urbanas é necessário um bom planejamento pensando-se em longo prazo, visto que uma árvore depois que cresce ocupa tanto espaços aéreos, como subterrâneos pelas suas raízes. Logo, se fazendo necessário o planejamento do local escolhido levando-se em consideração, além da espécie arbórea escolhida (grande, médio ou pequeno porte), e do espaço livre disponível para o plantio, levar em consideração elementos como fiações aéreas, semáforos, edificações, tubulações de água e esgoto presentes no subsolo.

Diante dessas colocações pode-se perceber com o estudo in loco realizado sobre a adequação da arborização do canteiro central da Avenida Rui Barbosa da Cidade de Garanhuns-PE, (figura 1) não foi adequadamente planejada, pois, a maioria das espécies arbóreas escolhidas para o plantio podem ser consideradas inadequadas, principalmente pelo tipo de raiz e expansão da copa de algumas árvores plantadas no canteiro dessa avenida. E, esses fatos geram ausência de sincronia entre o planejamento de arborização de um espaço livre e a espécie escolhida para esse mesmo espaço. 


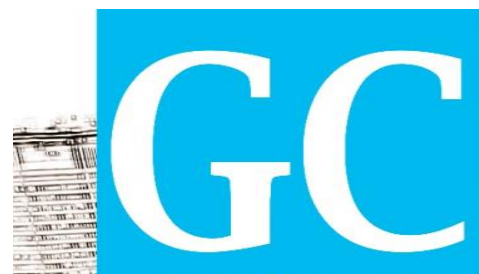

Revista Nacional de

Gerenciamento de Cidades
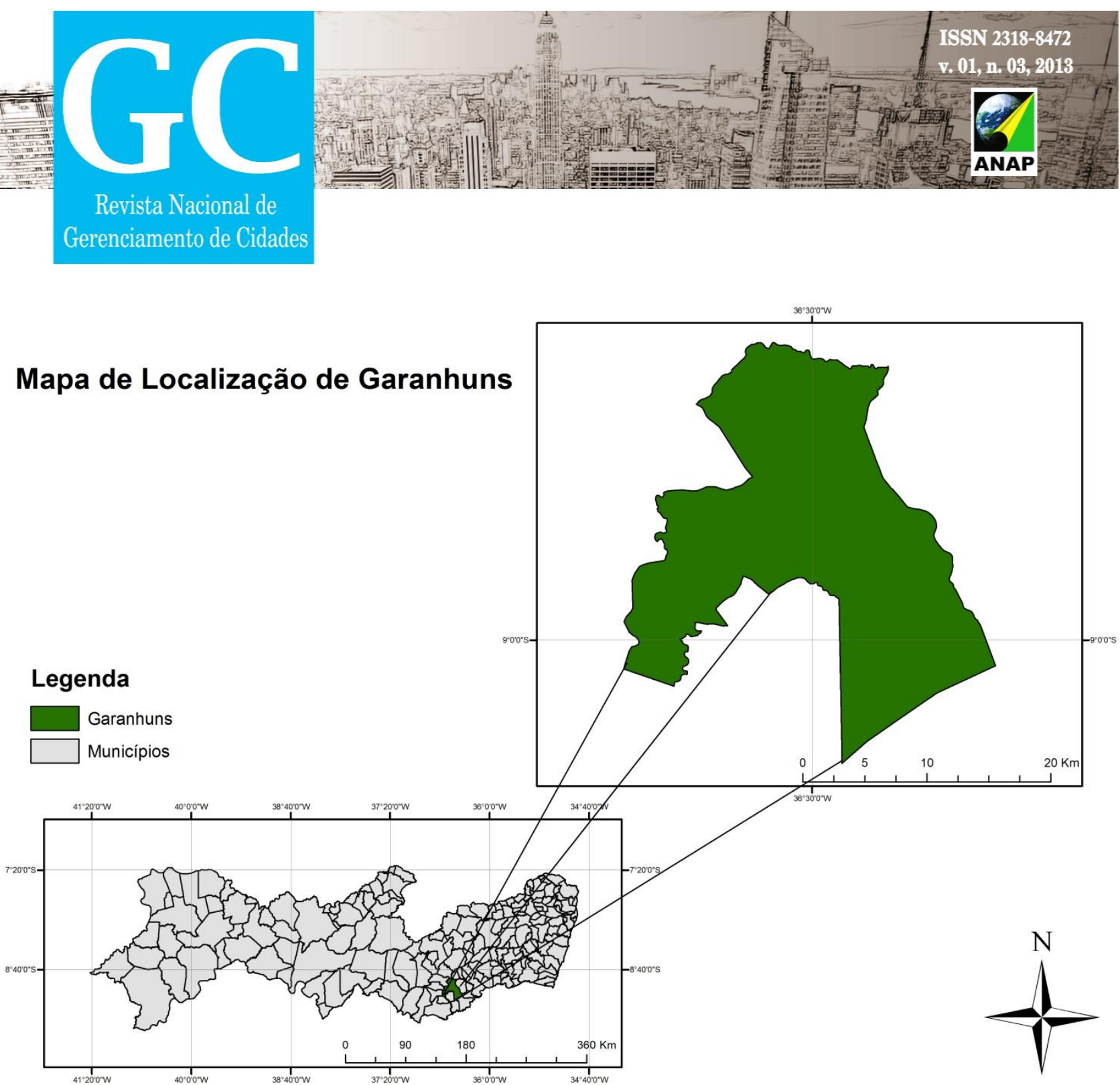

Figura 1 - Mapa de localização do Município de Garanhuns - PE, Fonte: Chaves 2013.

E como resultado dessa falta de sincronia, as raízes de algumas árvores acabam danificando os calçamentos do canteiro, suas copas acabas ficando muito próximas das edificações, por vezes junto à fiação elétrica, semáforos e de tubulações de esgoto. As árvores também são maltratadas em épocas de festivas que são comuns na cidade, pois nelas são colocados pregos para fixação de cartazes e muita vezes se observa galhos cortados ou quebrados, sem uma poda adequada, danificando a árvore e interferindo em sua longevidade.

Mas, salientando-se que segundo Henrique (2009), "o planejamento urbano difunde as ideias de claridade e espaços abertos do higienismo, mas também retoma o rigor geométrico e a monumentalidade das formas" (HENRIQUE, 2009, p.129). O planejamento 


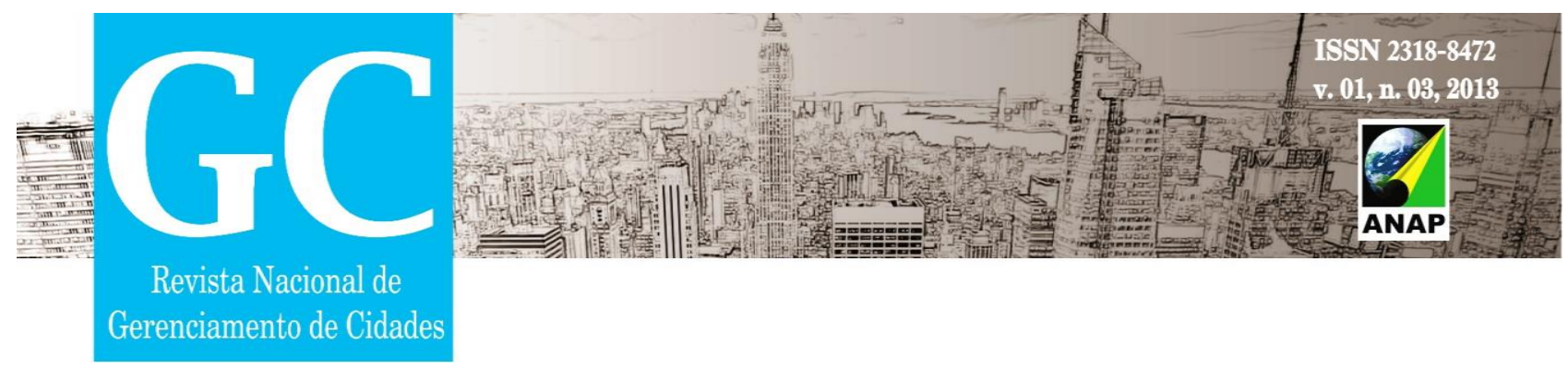

procura, então, uma melhor adequação aos espaços urbanos, além de melhorar as características da cidade em seus modos de ação e relação, respeitando as formas dadas as construções edificadas.

\section{RESULTADOS E DISCUSSÃO DA ADEQUAÇÃO DA ARBORIZAÇÃO PRESENTE NO CANTEIRO CENTRAL DA AVENIDA RUI BARBOSA}

A Avenida Rui Barbosa, município de Garanhuns - PE, foi aberta em 1925 pelo prefeito Euclides Dourado. Sua construção deu início ao povoamento do maior bairro de da cidade. Gradativamente tornou-se, também, um dos bairros nobres da cidade denominado Heliópolis. Nessa avenida está o único Relógio de Flores do norte e nordeste do país, e este, é praticamente o símbolo que identifica Garanhuns em termos nacional e até internacionalmente.

Atualmente a referida Avenida e predominantemente de função comercial, prestação de serviço. Porém, em uma de suas cabeceiras encontra-se a Praça Tavares Correia, na qual situa-se o Relógio das Flores, apresenta função turística. Ela tem um traçado ortogonal e equipamentos como bancos, passeios e edificação. E, por fazer parte de uma área nobre do município apresenta um bom sistema de água, coleta de lixo, drenagem pluvial e tem uma boa iluminação pública.

Retomando-se o canteiro central da avenida, verifica-se que é bem arborizado, porem a espécie predominante nessa arborização é inadequada para arborizar um espaço limitado como de um canteiro de avenida. As principais espécies presentes no canteiro da Av. Rui Barbosa são a Flamboyant, o lpê e a Castanhola. Dessas três, apenas o Ipê é espécie nativa, as outras duas são exóticas, a Flamboyant é africana e a Castanhola é asiática.

E essas espécies exóticas por não serem adequadas a estarem nesse espaço urbano resultam na ausência de sincronia entre planejamento e plantio da arborização urbana, pois no planejamento de arborizar o canteiro central da Av. Rui Barbosa, não foi levado em consideração a espécie arbórea escolhida. No caso do Flamboyant (Delonix 


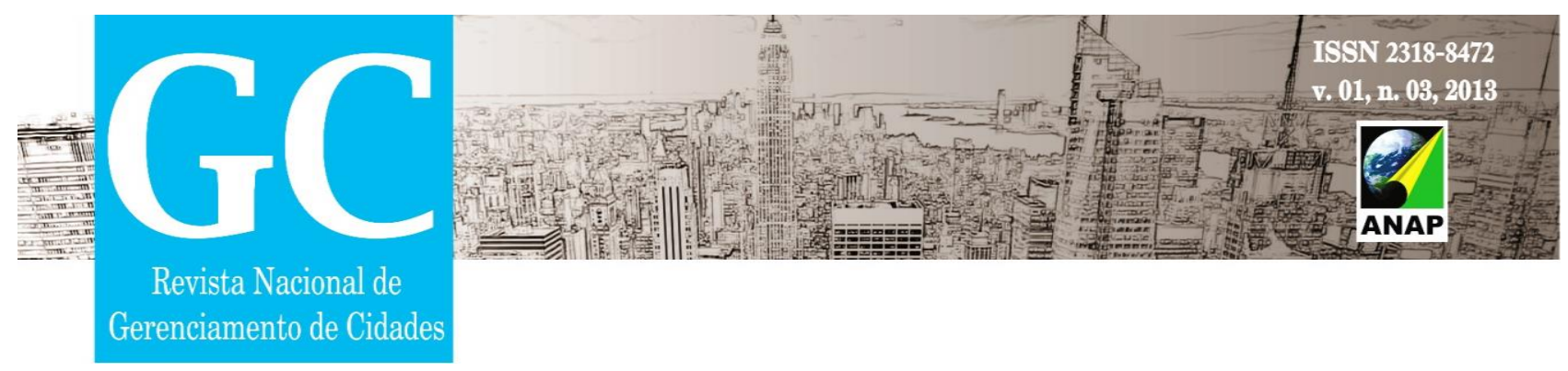

regia, figura 2), pertencente à família das Fabaceaes e de origem africana chega a ter entre 6 a 12 metros de altura e é considerado uma das árvores mais belas do mundo, devido ao colorido intenso de suas flores e suas raízes bastante agressivas, com parte delas acima da superfície, tornando-a imprópria para a ornamentação de calçadas, ruas ou próximas a tubulações de água, esgoto, paredes e até mesmo fiação elétrica

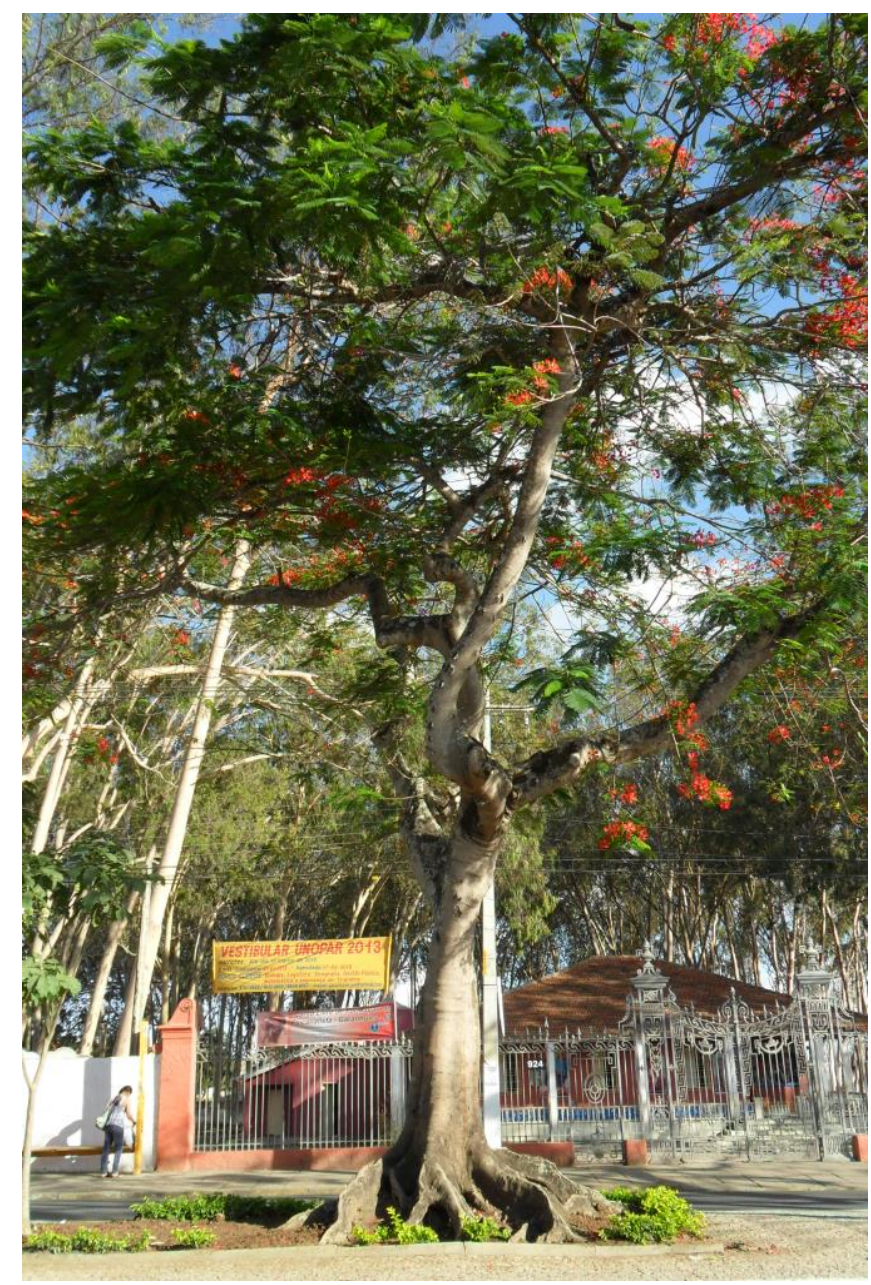

Figura 2: Flamboyant, espécie arbórea predominante no canteiro central da Av. Rui Barbosa Fonte: Chaves e Silva 2013

A castanhola (Terminalia catappa, figura 3), da família das Combretaceaes de origem asiática, chega a mais de 12 metros de altura. Ela apresenta caule ereto Sua copa 


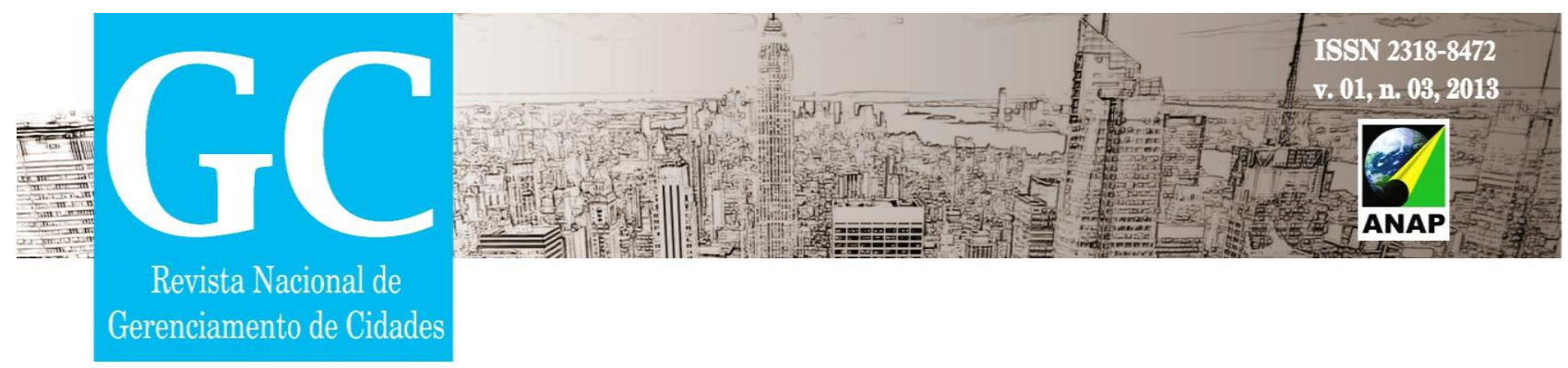

é incomum, formada por uma ramagem horizontal, agrupada a espaços regulares no tronco. É uma árvore indicada para as condições adversas do litoral. Sua copa ampla e cheia fornece sombra farta no escaldante verão dos trópicos. Não são indicadas para estacionamentos ou em locais com grande movimento de automóveis, pois os frutos ricos em ácidos podem manchar os automóveis.

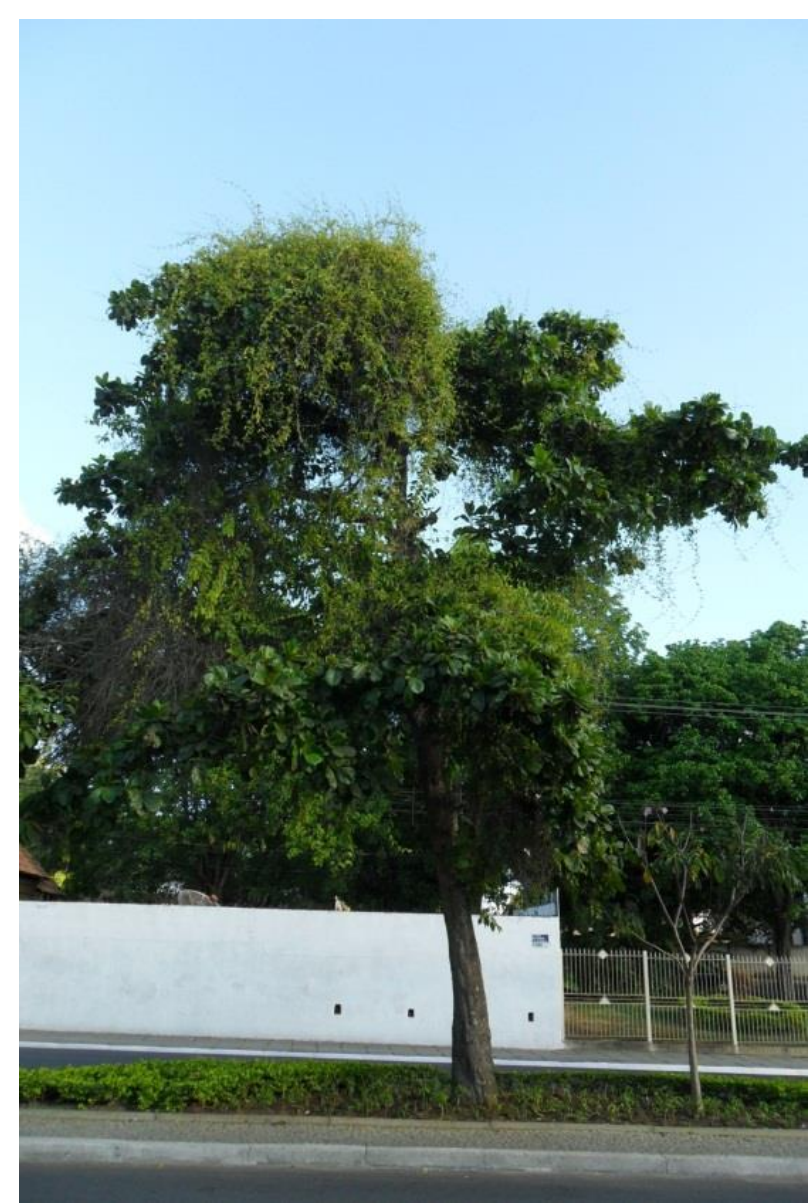

Figura 3: Castanhola, árvore predominante no canteiro central da Av. Rui Barbosa Fonte: Chaves e Silva 2013

E apenas o Ipê (Tabebuia impetiginosa, figura 4) é da família Bignoniaceae e originária da América do Sul, com altura entre 6 a 9 metros. É uma ótima árvore ornamental para arborização urbana, de crescimento moderado a rápido, que não possui raízes agressivas, sua floração é maravilhosa e recompensadora, além de atrair polinizadores, como beija-flores e abelhas, adapta-se bem a climas quentes, mas pode 


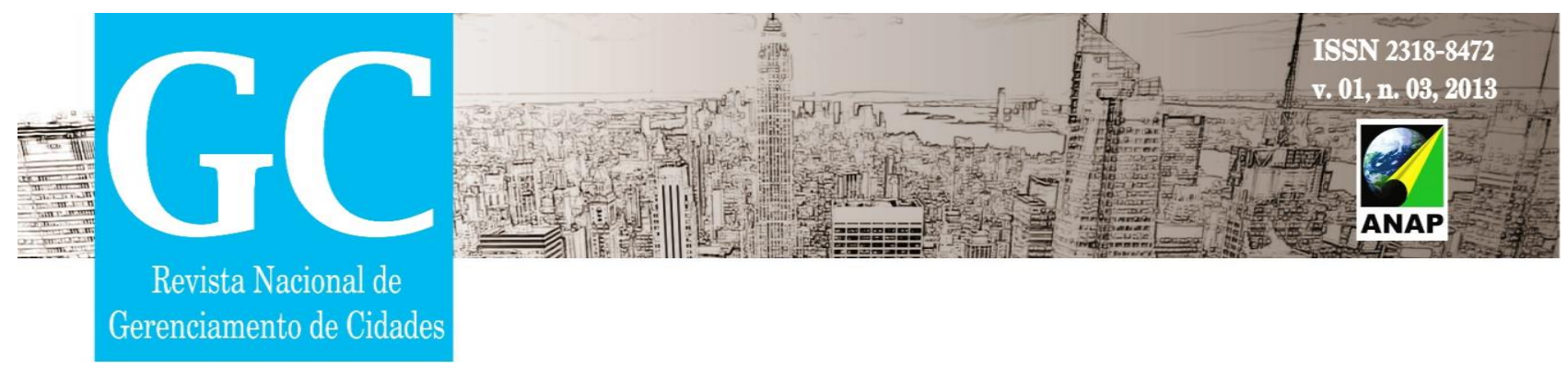

ser cultivada em regiões subtropicais, tendo nestes casos uma redução na velocidade de crescimento.

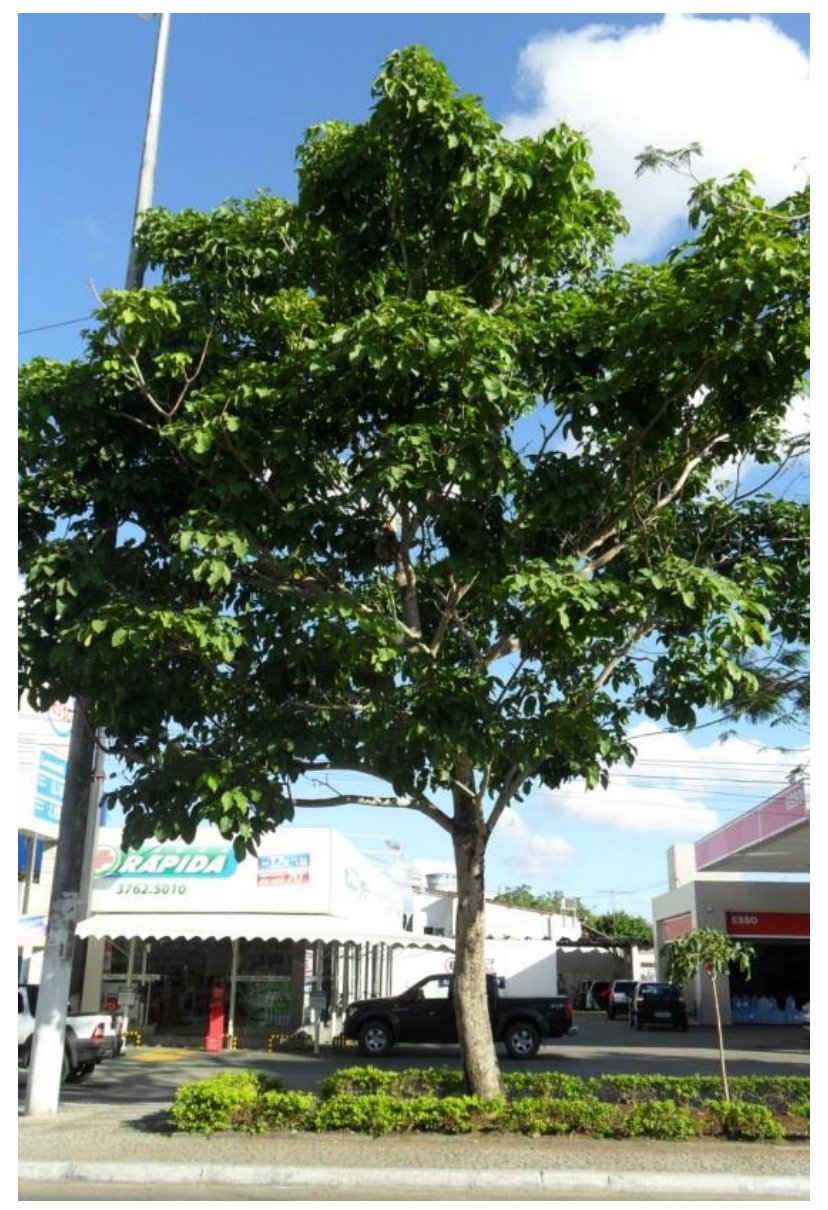

Figura 4: Ipê árvore nativa presente no canteiro central da Av. Rui Barbosa Fonte: Chaves e Silva 2013.

$\mathrm{Na}$ figura 5, apresenta-se a quantificação em porcentagem da predominância da espécie arbórea onde a espécie dominante não é adequada para tal espaço público, visto que as raízes danificaram o calçamento do espaço físico em tela. Verificou-se que a maior parte das espécies arbóreas é exótica, os galhos ficam próximos a edificações e fiação elétrica, não são bem podadas e apresentam problemas fitossanitários como, cupim, decomposição, principalmente no tronco, galhos secos entre outros. 


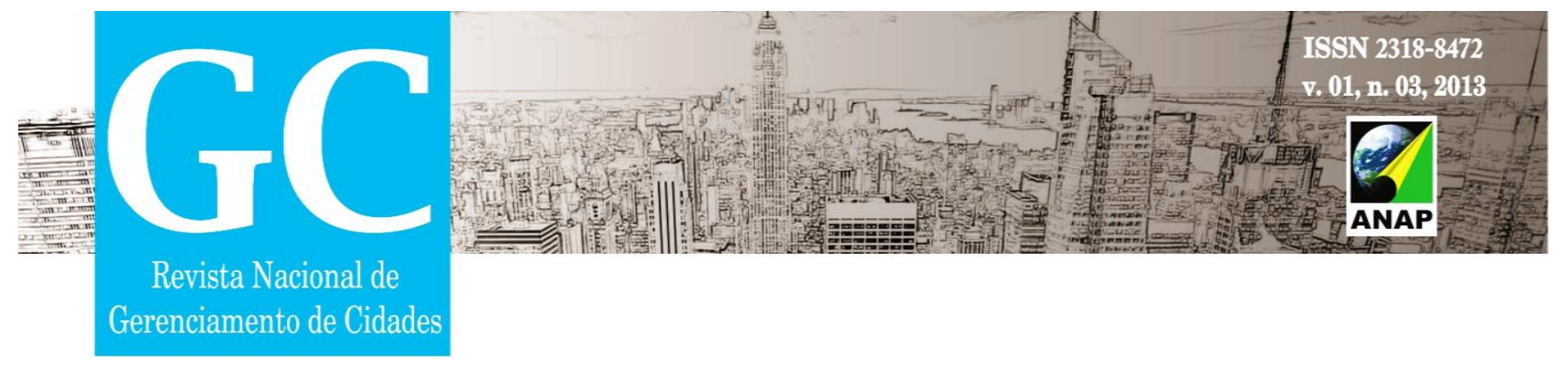

\section{Espécies Arbóreas Predominantes na Avenida Rui Barbosa, Garanhuns-PE}

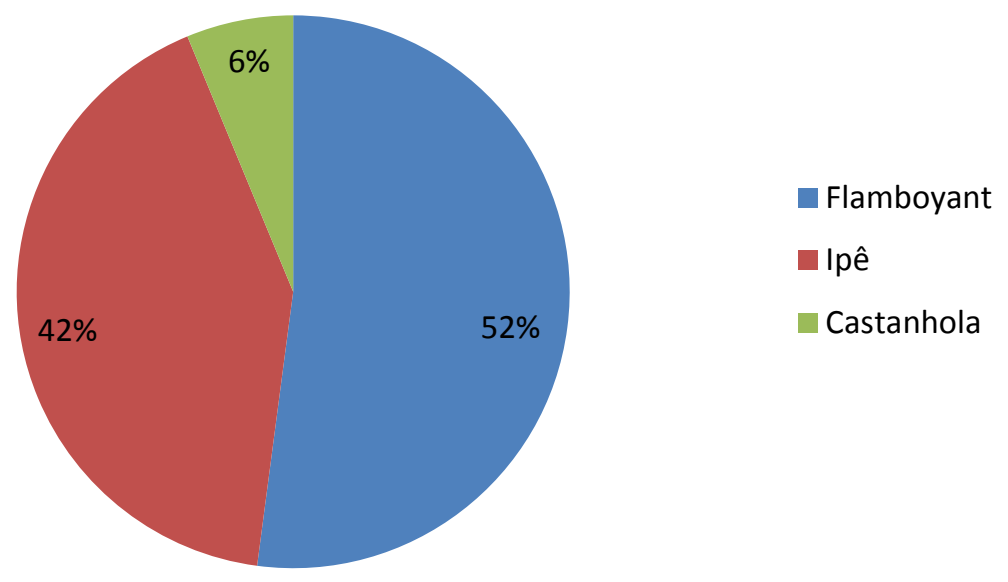

Gráfico 1: predominância das espécies arbóreas na A. Rui Barboza, Garanhuns-PE. Fonte: Chaves 2013.

Assim, fica evidente um dos principais motivos responsáveis pela falta de sincronia entre planejamento e plantio da arborização urbana no espaço público da Avenida Rui Barbosa em Garanhuns-PE, que é falta de estudo em relação à espécie arbórea adequada a ser plantada.

De acordo com o Manual de Arborização urbana, os seres humanos constroem seus ambientes para neles viverem e dele retirarem suas necessidades, e a cidade é construída para melhorar e facilitar a vida dos homens, porem ela é uma construção planejada é artificial, fazendo-se necessário a introdução de elementos naturais, para melhorar a vida dos seres vivos urbanos (homens, animais, insetos, etc.). Assim, são criados espaços livres destinados à arborização e que, além de estratégia de amenização de aspectos ambientais adversos, é importante sob os aspectos ecológico, histórico, cultural, social, estético e paisagístico, contribuindo para:

- A manutenção da estabilidade microclimática;

- O conforto térmico associado à umidade do ar e à sombra;

- A melhoria da qualidade do ar; 


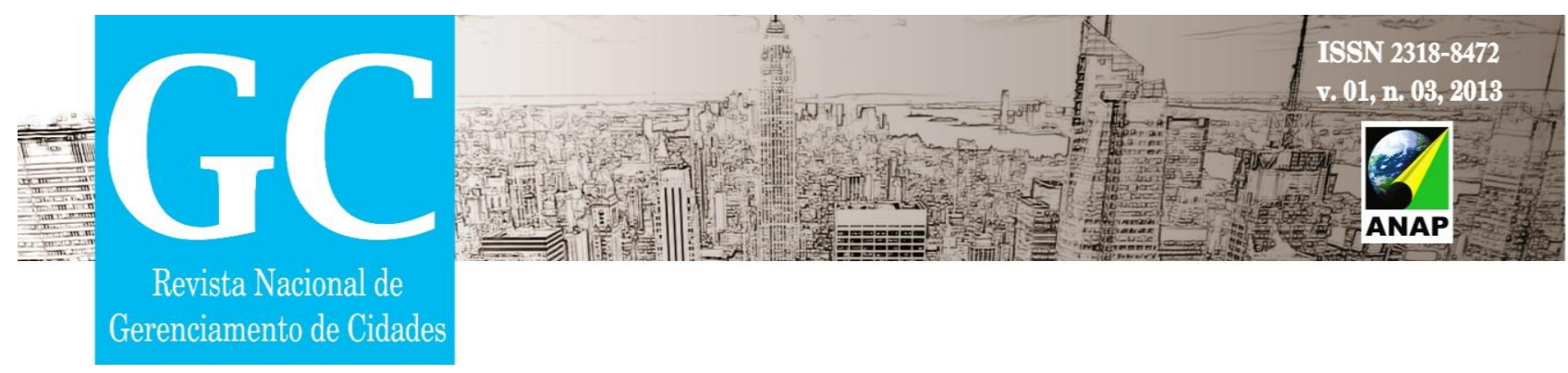

- A redução da poluição;

- A melhoria da infiltração da água no solo, evitando erosões associadas ao escoamento superficial das águas das chuvas;

- A proteção e direcionamento do vento;

- A proteção dos corpos d'água e do solo;

- A conservação genética da flora nativa;

- O abrigo à fauna silvestre, contribuindo para o equilíbrio das cadeias alimentares, diminuindo pragas e agentes vetores de doenças;

- A formação de barreiras visuais e/ou sonoras, proporcionando privacidade;

- O cotidiano da população, funcionando como elementos referenciais marcantes;

- O embelezamento da cidade, proporcionando prazer estético e bem-estar psicológico;

- O aumento do valor das propriedades; e,

- A melhoria da saúde física e mental da população.

Esses fatores e a ação antrópica tornam as cidades organizações sistêmicas e complexas: sistêmicas, porque seus variados aspectos precisam ser compreendidos como uma totalidade, onde os homens necessitam da natureza e das construções artificias para melhorar suas condições de vida e esses fatores são vistos em conjunto e não isolados; e complexas, porque devem ser entendidas e analisadas através das muitas relações que estabelecem homem meio ambiente, homem meio ambiente urbano, meio ambiente e meio ambiente urbano.

E a falta de sincronia entre a arborização e o planejamento das cidades tornam os espaços livres desestruturados, onde a população que necessita dessa área para seu lazer acaba por não poder desfrutar desses ambientes, pois o mesmo apresenta calçamento danificado pela falta de compatibilidade da raiz da espécie arbórea e o espaço físico destinado ao plantio. Infelizmente pode-se ter a vida em risco por causa de acidentes devido à falta de observância desses detalhes de suma importância, ou seja, considerar a árvore com o espaço aéreo por causa fiação elétrica junto aos galhos. $O$ fato da inobservância desse fator pode gerar algum acidente evidenciando, também, falta de 


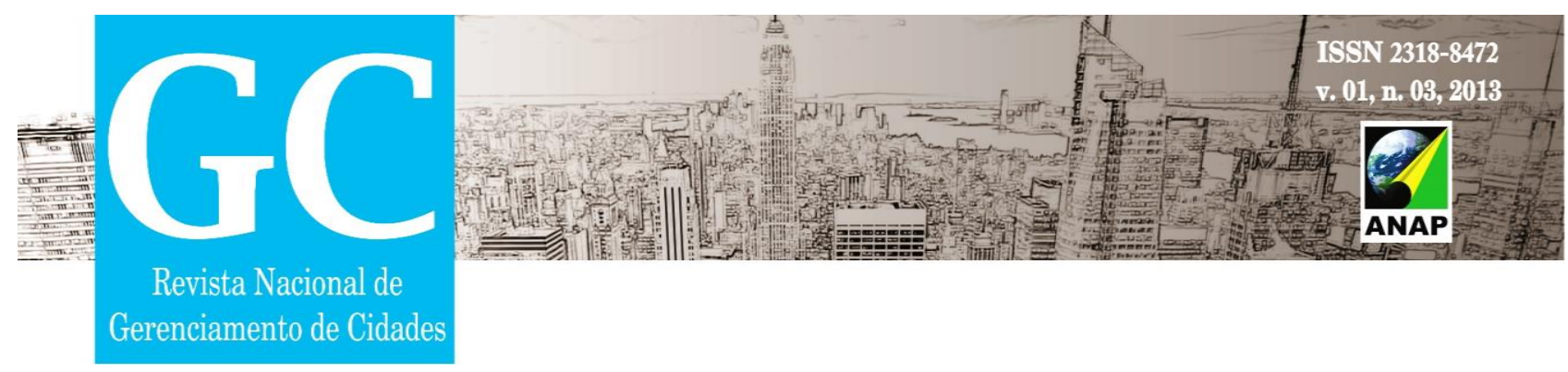

sincronia com as tubulações de água e esgoto que, se danificados prejudicam enormemente a população que precisa delas para ter água em seus lares.

Outro fator relevante da arborização e a função paisagística desempenhada. esta valoriza o espaço do ponto de vista estético e, se tratando da arborização do canteiro central da Av. Rui Barbosa tem-se a valorização econômica por ser parte de um dos pontos turísticos da cidade de Garanhuns-PE, o Relógio das Flores. Por esses motivos, a arborização não deveria apresentar essa falta de sincronia com o planejamento deste local, bem como, se deveria ter um estudo aprofundado das espécies adequadas para comportar a esse espaço evitando-se, assim, problemas derivados da falta de sincronia e/ ou harmonização.

\section{CONSIDERAÇÕES}

Os dilemas da sustentabilidade urbana são muitos, entre eles a falta de sincronia entre o planejamento urbano e a arborização. Assunto esse de extrema importância quando se falar no bem estar da população das cidades, já que a introdução desses espaços verdes beneficiam a população contribuindo para ambientes mais saudáveis e confortáveis, pois entre diversos benefícios a arborização ajuda a minimizar o impacto das chuvas facilitando a infiltração das águas no solo e amortecer os impactos dos pingos de chuva diretamente no solo, evitando assim a probabilidade de enchentes.

Também ajuda na amenização das altas temperaturas, tão comuns em cidades do nordeste brasileiro, além de outros benefícios advindos da arborização urbana. Mas, o que se ressaltou no presente trabalho foi à necessidade de se ter um planejamento mais adequado referente ao plantio de árvores em espaços urbanos, principalmente quando esse espaço é limitado como o do canteiro central aqui tratado.

Foi verificado que o canteiro central da av. Rui Barbosa é um espaço limitado entre duas vias de grande movimento de veículos e pessoas, cercado de objetos urbanos como 

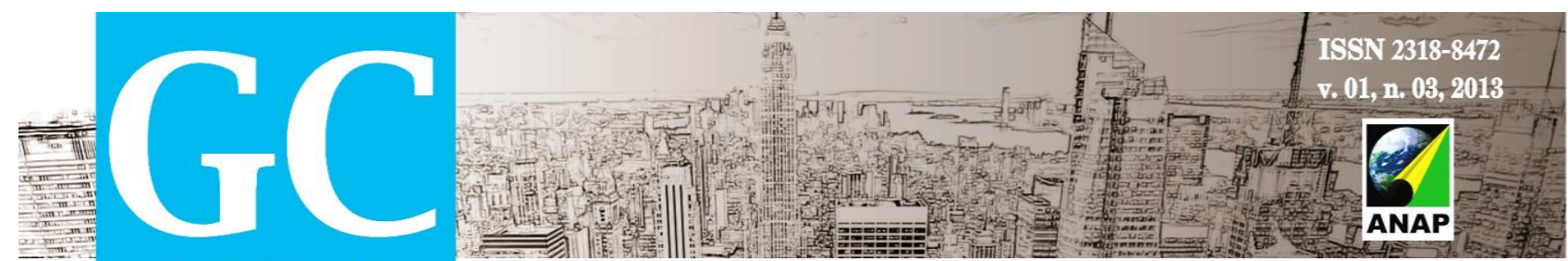

Revista Nacional de

Gerenciamento de Cidades

fiação elétrica, edifícios grandes semáforos e tubulações subterrâneas entre outros elementos. Logo, é necessário um estudo adequado sobre as espécies escolhidas para arborizar esse espaço urbano, bem como estudar o espaço em si e seu tamanho.

Nesse sentido, ao se estudar as espécies arbóreas pode-se saber seu tipo de raiz, tamanho, expansão da copa, frutos, elementos necessários para a escolha e definição do espaço adequado ao seu plantio. Fato esse que se pode dizer, muito provavelmente, não ter sido levado em consideração quando escolheram a principal espécie arbórea dessa avenida, uma vez que, a Flamboyant é uma espécie de grande porte, de raiz agressiva que necessitada de grande espaço para seu desenvolvimento e também é exótica, resultando na falta de sincronia entre a arborização do canteiro central da Av. Rui Barbosa de Garanhuns-PE e seu planejamento.

Faz-se, assim, necessário um estudo sobre essa arborização para que essa escolha inadequada não venha a prejudicar o espaço em que as árvores estão plantadas, ou cause algum acidente que afete a população, já que boa parte das árvores está danificada e, em sua maioria no tronco, os quais se se apresentam deteriorados, com cupim e, muita delas, com aparência de estarem secas e, quase mortas. Além de ser visível que o calçamento próximo às árvores Flamboyant apresenta-se danificado.

Mas, independentemente do espaço escolhido para o plantio de uma árvore, seus benefícios são nítidos pois, segundo os estudos sobre a influencia da arborização, influenciam beneficamente na temperatura da superfície e na umidade relativa do ar do ambiente urbano, segundo Laurie em Schutzer (2012) apud Mascaró (1978).

Nesse estudo, organizado no quadro abaixo, é possível ver o quanto a presença arbórea deixa o ambiente urbano mais agradável e saudável na vida das cidades. 


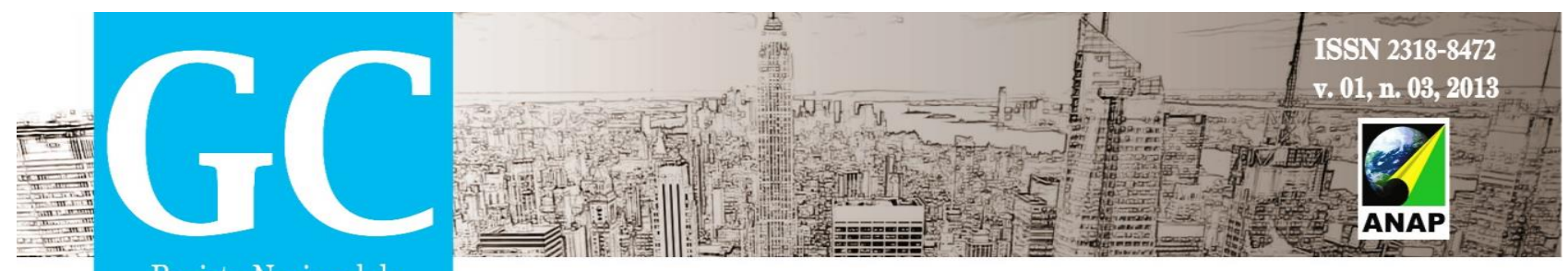

Revista Nacional de

Gerenciamento de Cidades

Quadro 1:

\begin{tabular}{|c|c|c|c|c|c|}
\hline \multicolumn{5}{|c|}{ Temperaturas superficiais de diferentes tipos de pisos do ambiente urbano } \\
\hline $\begin{array}{c}\text { Temperaturas } \\
{ }^{\circ} \mathrm{C}\end{array}$ & $50^{\circ} \mathrm{C}$ & $17^{\circ} \mathrm{C}$ & $37^{\circ} \mathrm{C}$ & $47^{\circ} \mathrm{C}$ & $35^{\circ} \mathrm{C}$ \\
\hline Tipos de Pisos & Asfalto ao Sol & Grama a & Concreto a & Concreto ao & Grama ao Sol \\
& & Sombra & Sombra & Sol & \\
\hline
\end{tabular}

Quadro 2:

\begin{tabular}{|l|c|c|c|}
\hline \multicolumn{4}{|c|}{$\begin{array}{c}\text { Diferentes temperaturas entre as áreas expostas ao sol e as áreas sombreadas por algumas árvores } \\
\text { de Porto Alegre, no verão }\end{array}$} \\
\hline Área exposta ao sol $\left({ }^{\circ} \mathrm{C}\right)$ & $35^{\circ} \mathrm{C}$ & $36^{\circ} \mathrm{C}$ & $37,5^{\circ} \mathrm{C}$ \\
\hline Área sombreada $\left({ }^{\circ} \mathrm{C}\right)$ & $30,5^{\circ} \mathrm{C}$ & $22^{\circ} \mathrm{C}$ & $33^{\circ} \mathrm{C}$ \\
\hline Espécie arbórea & Cinamomo & Sibipiruna & Extremosa \\
\hline
\end{tabular}

Quadro 3:

\begin{tabular}{|l|c|c|c|}
\hline \multicolumn{3}{|c|}{ Diferenças de umidade relativa do ar entre áreas expostas a radiação solar e as áreas sombreadas } \\
por três tipos de árvores de Porto Alegre, no verão \\
\hline Área exposta ao sol (\%) & $40 \%$ & $32 \%$ & $37 \%$ \\
\hline Área sombreada (\%) & $55 \%$ & $52 \%$ & $42 \%$ \\
\hline Espécie arbórea & Ligustro & Sibipiruna & Jacarandá \\
\hline
\end{tabular}

Esse estudo, colocado em quadros, demostram o quanto a árvore é benéfica ao ambiente das cidades, contribuindo principalmente para o convívio harmônico dos elementos naturais e artificiais, os quais devem estar em sincronia, para não se tornarem maléficos ao espaço ocupado.

\section{REFERÊNCIAS}



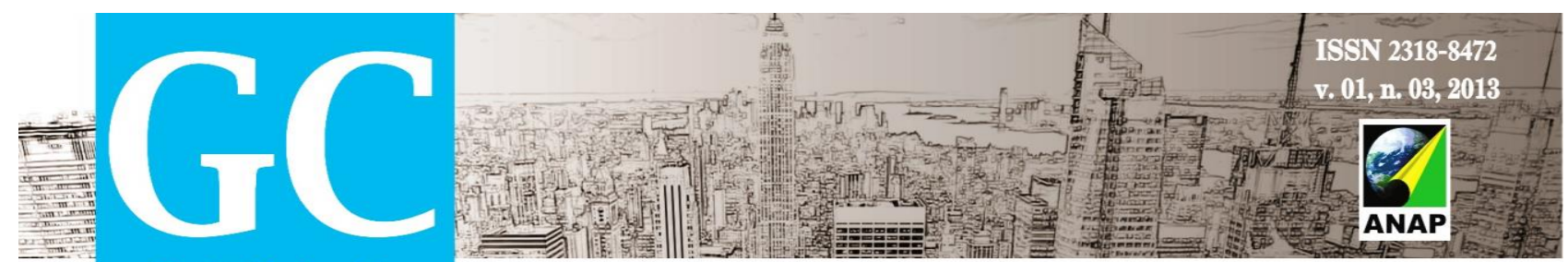

Revista Nacional de

Gerenciamento de Cidades

Companhia Energética de Minas Gerais. Manual de arborização. Belo Horizonte:

Cemig/Fundação Biodiversitas, 2011. Disponível em: <www,comig.com.br/.../Manual-

Arborização-Cemig-biodiversidade.pd... acesso em 22/02/2012.

O que é planejamento Disponível em:

<http://www.administradores.com.br/artigos/administracao-e-negocios/> Acesso em: 07 de julho, 2013.

RESENDE, W. X; SOUZA, R. L. Concepção e controvérsias sobre áreas verdes urbanas. SOUZA, R. M. Território, planejamento e sustentabilidade. São Cristóvão; UFS, 2009.

CARNEIRO, Ana Rita; MESQUITA, Liana de Barros. Espaços livres de Recife. Recife: prefeitura da cidade do recife/Universidade Federal de Pernambuco, 2000.

NETO, Evaldo Marques de Lima; SOUZA, Rosemeri Melo. Arborização urbana: gênese e relevância no planejamento territorial. SOUZA, Rosemeri Melo: Território, planejamento e sustentabilidade. São Cristóvão: UFS, 2009.

SCHUTZER, José Guilerme. Cidade e meio ambiente: a apropriação do relevo no desenho ambiental urbano. São Paulo: Ed. Universidade de São Paulo, 2012. 